\title{
BDJ Open (2019-2020) and the advantages of open access publishing
}

\author{
Jonathan Lewney'
}

\section{Key points}

Examines papers published in BDJ Open between 2019 and 2020 to highlight which areas researchers felt were important to publish open access.
Discusses the advantages of open access publishing to authors, readers and the scientific community.
Explores how open access publishing has allowed the BDJ Portfolio to publish a far wider range of research both geographically and subject-wise.

\begin{abstract}
BDJ Open is the open access sister journal to the British Dental Journal, and this paper aims to explore the various different articles that BDJ Open has published between 2019 and 2020, in order to highlight which areas authors felt were important to publish open access. Furthermore, this article will investigate the advantages of open access publishing to both authors and readers, as well as the scientific community in general, and will examine how open access publishing has allowed the BDJ Portfolio to publish a wide range of research, both in terms of topic and geography.
\end{abstract}

\section{Introduction}

$B D J$ Open is the open access, online-only journal from the British Dental Association (BDA) and Springer Nature. BDJ Open 'opened' in 2015 and has greatly increased both the scope, and the reach, of the BDJ Portfolio. Traditional funding for journals has been through the subscription model, under which institutions (such as universities) pay a subscription to receive the journal. Subscription through a membership organisation, such as the BDA, also allows a further funding source, as does advertising revenue. A mixture of these has traditionally funded the British Dental Journal (BDJ) and ensured that authors do not have to pay to have their work published. The disadvantage of this model is that only those who subscribe to the journal can access content. Conversely, open access journals are, as the name suggests, open to anyone provided they have an internet

'Associate Editor, BDJ Portfolio, UK. Correspondence to: Jonathan Lewney Email address: jonathan.lewney@bda.org

Accepted 19 November 2021

https://doi.org/10.1038/s41415-021-3722-4 connection. Authors who wish to publish open access pay an 'Article Processing Charge' (or 'APC') after acceptance following peer review but before publication and these charges then fund the running costs of the journal. Some subscription journals also offer the opportunity for authors to pay to allow their content to be open access. This is called a 'hybrid' journal and the $B D J$ is an example of this.

One of the advantages of open access publishing is that people in lower-income countries are able to view journal content. Subscriptions to journals can be prohibitively expensive to many institutions in Africa, Asia and other parts of the world. However, APCs for authors in these countries are likely to be beyond what they are able to pay. For this reason, BDJ Open, along with many other open access journals in the Springer Nature portfolio, offer an 'APC waiver' when the first author is from a country that the World Bank has designated as a 'low-income economy.' A $50 \%$ discount is offered to people from countries designated a 'lower middle-income economy'. Research from low-income countries is an important addition to the body of scientific knowledge, but if this is not of interest to the main audience of a subscription journal, then this can be difficult to publish. BDJ Open has published a number of articles from low-income countries and these can all be accessed by clinicians and researchers across the globe.

Other benefits of open access publishing include:

- A vastly expanded scope (there are no confines in terms of publishing space);

- Relatively short publication timeframes (no need to wait for space in the print copy); and

- The obvious advantage that anyone can access an open access article without the need for subscriptions, logins or access to the physical journal.

As there are far fewer constraints on space, essentially many more topics within the scope of oral and dental health are potentially publishable. The content is largely driven by what authors and/or their institutions feel should be published. BDJ Open therefore gives the opportunity to examine what authors are keen to publish, as well as what editors feel is within scope and of interest to readers. We looked at the papers published from 2019 to 2020 and grouped them into different categories to see which areas authors felt were important to publish open access. 


\section{Dental professionals}

A high number of submissions to clinical journals report early findings of potential new products or technologies proposing that these should be tested clinically (novel additions to toothpastes are a good dental example). These can be termed 'pre-clinical,' 'in vitro' or 'ex vivo' studies. Many clinical, open access journals publish a high proportion of these as, although researchers are keen to publish them, they would otherwise be unlikely to be of interest to a more general readership. In BDJ Open, however, the largest proportion of published manuscripts in 2019-2020 $(\mathrm{n}=10)$ focused on the experience of dental professionals $\mathrm{s}^{2,3,4}$ and/or dental students. ${ }^{5,6,7,8}$ This included manuscripts describing the experience of dentists from Finland ${ }^{9}$ to South Africa ${ }^{10}$ and Sierra Leone. ${ }^{11}$ It might be difficult to argue these would be of sufficient interest to the general $B D J$ readership to justify publication space in the print journal, but the authors of these were keen to publish their work and as $B D J$ Open is open access, the general $B D J$ readership can still access these, providing important extra advantages.

One publication also outlined the role pharmacists have in oral healthcare, with respect to management of medication-related osteonecrosis of the jaw. ${ }^{12}$

\section{Patient experience}

Seven papers ${ }^{13,14,15,16,17,18,19}$ explored the experiences of patients and the public in oral health and oral healthcare, ranging from the $\mathrm{UK}^{13}$ to Sweden ${ }^{14}$ and Spain. ${ }^{19}$ Again, it is encouraging to see that both the authors of such papers, and the institutions which fund them, see the value of open access publishing.

\section{Pre-clinical/ex vivo}

As outlined above, open access journals are usually a very popular choice for authors with papers reporting the category of preclinical/ex vivo studies. It is interesting to note that the same number of papers in this

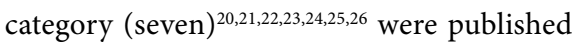
in 2019-2020 as those reporting the results of evaluations/studies into patient experience. $B D J$ Open was able to publish early-stage findings from some well-established research teams. Souror et al.'s paper 'Evaluation of a novel fixed-space maintainer made of lightcured acrylic resin: an in vitro study' ${ }^{20}$ also gave the opportunity to publish a more novel solution to a familiar clinical problem, when the available resources differ from what might be found in a dental clinic or hospital in the
UK. This would have been unlikely to be of interest to UK clinicians, but having an open access journal in the BDJ Portfolio enables this knowledge to be shared worldwide.

\section{Clinical}

\section{Health technology assessment/clinical} interventions

Studies which examine the effects on patients (in vivo) of clinical procedures are generally more likely to be of interest to the wider clinical community than earlier in vitro/ex vivo studies. Yet, for broad appeal to clinicians, they generally have to be conclusive enough to warrant changes in clinical practice, or at least consideration of this. Open access publishing offers a useful way for researchers to share pilot studies and early-phase clinical trials. $B D J$ Open does, however, publish full clinical trials, and again, the results of these can be accessed by anyone with an internet connection which helps with dissemination of new knowledge. There were eight such papers published in $B D J$ Open in 2019-2020, ${ }^{27,28,29,30,31,32,33,34}$ on topics including experimental dentine hypersensitivity toothpastes ${ }^{27}$ and smartphone applications. ${ }^{30}$

\section{Epidemiology}

Epidemiological research aims to compare different groups (or 'before and after' data in the same group) to examine the incidence, distribution and possible control of diseases and other factors relating to health. There were four papers published in BDJ Open reporting the results of such studies. ${ }^{35,36,37,38}$ One other paper was also published which highlighted lessons learned from a study which failed to find a statistically significant result. ${ }^{39}$ Such papers reporting methodological issues are of more interest to researchers than to the broader clinical community, and open access publishing is the ideal vehicle for the dissemination of this knowledge.

\section{Broader applications of dentistry}

Another advantage of open access publishing is the ability to share new learning around very specific topics. Many subscription journals are so specialised that they reach only a very small audience. Again, open access publishing removes those barriers. There were four such papers published in 2019-2020, ${ }^{40,41,42,43}$ including Chetty et al.'s 'Dentinogenesis imperfecta in osteogenesis imperfecta type XI in South Africa: a genotype-phenotype correlation' ${ }^{41}$ and Khan et al.'s 'Analysis of different characteristics of smile. ${ }^{43}$

\section{Systematic reviews}

Finally, although BDJ Open does not currently publish 'narrative' reviews, it does publish systematic reviews which generate new results. The BDJ Portfolio has a number of publications which publish systematic reviews and the advantages of open access publishing remain attractive to authors of such articles. Two were published in BDJ Open between 2019 and 2020 - one comparing the DMFT index between thalassemia major patients and a control group, ${ }^{44}$ and one investigating aerosol, splatter and droplet contamination associated with oral surgery in the context of COVID-19. ${ }^{45}$

\section{Conclusion}

Open access publishing offers many advantages over subscription-only publishing - to authors, readers and to the scientific community in general. A particularly exciting aspect of open access publishing for the BDJ Portfolio has been the ability to publish a far wider range of research, both in terms of topic and geography. $B D J$ Open continues to grow and we look forward to providing an update to this paper in the future.

\section{Ethics declaration}

The author declares no conflicts of interest.

\section{References}

1. Springer Nature. APC waivers and discounts. Available at https://www.springernature.com/gp/ open-research/policies/journal-policies/apc-waivercountries (accessed November 2021).

2. Moodley R, Van Wyk J. Multidisciplinary perspectives to prevent occupational health-related conditions among dental practitioners. BDJ Open 2019; DOI: 10.1038/s41405-019-0010-3

3. Aly M, Elchaghaby M A. Impact of novel coronavirus disease (COVID-19) on Egyptian dentists' fear and dental practice (a cross-sectional survey). BDJ Open 2020; DOI: 10.1038/s41405-020-00047-0.

4. Davda L S, Radford D R, Scambler S, Gallagher J E. Profiles of registrant dentists and policy directions from 2000 to 2020. BDJ Open 2020; DOI: $10.1038 /$ s41405-020-00054-1.

5. Sharma A, Chaudhari B K, Shrestha B et al. Knowledge and Perception about Dental Implants among Undergraduate Dental Students. BDJ Open 2019; DOI: 10.1038/s41405-018-0009-1.

6. Chowdhury C, Khijmatgar S, Chowdhury A, Harding $S$, Lynch $E$, Gootveld M. Dental anxiety in first- and final-year Indian dental students. BDJ Open 2019; DOI: 10.1038/s41405-019-0017-9.

7. Aljefri M, Williams J. The perceptions of preclinical and clinical dental students to altered smile aesthetics. BDJ Open 2020; DOI: 10.1038/ s41405-020-00045-2.

8. Al-wesabi A A, Abdelgawad F, Sasahara H, El Motayam K. Oral health knowledge, attitude and behaviour of dental students in a private university. BDJ Open 2019; DOI: 10.1038/s41405-019-0024-x.

9. Widström E, Tiira H, Tillberg A. Public Dental Service (PDS) personnel facing a major health care reform in Finland. BDJ Open 2019; DOI: 10.1038/ s41405-019-0012-1. 
10. Khan S B. Translation of the shortened dental arch research into clinical practice: A Stakeholder Mapping Approach. BDJ Open 2020; DOI: 10.1038/ s41405-020-0039-3.

11. Ghotane S G, Challacombe S J, Gallagher J E. Fortitude and resilience in service of the population: a case study of dental professionals striving for health in Sierra Leone. BDJ Open 2019; DOI: 10.1038/ s41405-019-0011-2.

12. Sturrock A, Preshaw P M, Hayes C, Wilkes S. A critical synthesis of the role of the pharmacist in oral healthcare and management of medication-related osteonecrosis of the jaw. BDJ Open 2020; DOI: 10.1038/ s41405-020-0043-7.

13. Witton R, Smith W. A service evaluation of the "Open Wide and Step Inside" school oral health programme. BDJ Open 2019; DOI: 10.1038/s41405-019-0013-0.

14. Pälvärinne R, Birkhed D, Forsberg B, Widström E. Visitors' experiences of public and private dental care in Sweden 1992-2012. BDJ Open 2019; DOI: 10.1038/ s41405-019-0020-1.

15. Shrestha B, Basnet B B, Adhikari G. A questionnaire study on the impact on oral health related quality of life by conventional rehabilitation of edentulous patient. BDJ Open 2020; DOI: 10.1038/s41405-020-0029-5.

16. Pickering K, Bissett S M, Holliday R, Vernazza C, Preshaw $\mathrm{P}$ M. Exploring the use of mouth guards in Muay Thai: a questionnaire survey. BDJ Open 2020; DOI: 10.1038/s41405-020-00048-z.

17. Momin P, Mahmood S. A Quality Improvement Project to Assess the Use of Visual Aids To Improve Understanding And Motivation In Periodontal Patients. BDJ Open 2020; DOI: 10.1038/s41405-020-0041-9.

18. Iomhair A N, John M. Facilitating Patient-Centred Care for Special Care Dentistry patients: A Quality Improvement Project in the Community Dental Service. BDJ Open 2020; DOI: 10.1038/s41405-020-0038-4.

19. Shadrav A, Kalenderian E, Roig P. "7/12" Patient Touch Point Strategy: A Novel Method to Increase Patient Loyalty and Encourage Preventative Care. BDJ Open 2019; DOI: 10.1038/s41405-019-0023-y.

20. Souror Y R, Maaly T, Khawandanah M S. Evaluation of a Novel Fixed Space Maintainer Made of Light Cured Acrylic Resin; An in Vitro Study. BDJ Open 2020; DOI: 10.1038/s41405-020-00046-1.

21. Al-Taee L, Deb S, Banerjee A. An In-Vitro Assessment of the Physical Properties of Manually-Mixed and Encapsulated Glass Ionomer Cements. BDJ Open 2020; DOI: 10.1038/s41405-020-0040-X.

22. Wang T-Y, Xu S-L, Wang Z-P, Guo J-Y. Mega-oss and Mega-TCP versus Bio-Oss granules fixed by alginate gel for bone regeneration. BDJ Open 2020; DOI: 10.1038/ s41405-020-0042-8.

23. Hegde M N, Gatti P, Hegde N D. Protection of wear resistance behaviour of enamel against electron beam irradiation. BDJ Open 2019; DOI: 10.1038/ s41405-019-0021-0.

24. Amaechi B T, AbdulAzees P A, Okoye L O, Meyer F, Enax J. Comparison of Hydroxyapatite and Fluoride Oral Care Gels for Remineralization of Initial Caries: A pH-cycling study. BDJ Open 2020; DOI: 10.1038/ s41405-020-0037-5.

25. Amaechi A T, AbdulAzees P A, Alshareif D 0 et al. Comparative Efficacy of a Hydroxyapatite and a Fluoride Toothpaste for Prevention and Remineralization of Dental Caries in Children. BDJ Open 2019; DOI: 10.1038/ s41405-019-0026-8.

26. Shacham M, Levin A, Shemesh A, Lvovsky A, Itzhak J B, Solomonov M. Accuracy and Stability of Electronic Apex Locator Length Measurements in Root Canals With Wide Apical Foramen: An Ex Vivo Study. BDJ Open 2020; DOl: 10.1038/s41405-020-00052-3.

27. Mason S, Young S, Araga M etal. Stain control with two experimental dentin hypersensitivity toothpastes containing spherical silica: a randomised, early-phase development study. BDJ Open 2019; DOI: 10.1038/ s41405-019-0016-x.

28. Siddique R, Nivedhitha M S, Ranjan M, Jacob B, Solete P. Comparison of Antibacterial Effectiveness of Three Rotary file System with Different Geometry in Infected Root Canals Before and After Instrumentation - A Double-Blinded Randomized Controlled Clinical Trial. BDJ Open 2020; DOI: 10.1038/s41405-020-0035-7.

29. Soileau K M, DeGenova A E, Yu Q. Blood pressure monitoring following the use of multiple carpules of anaesthetic utilizing a computer-controlled anaesthetic delivery system. BDJ Open 2020; DOI: 10.1038/ s41405-020-00049-y.

30. Farhadifard H, Soheilifar S, Farhadian M, Kokabi H Bakhshaei A. Orthodontic patients' oral hygiene compliance by utilising a smartphone application (Brush DJ): a randomized clinical trial. BDJ Open 2020; DOI: 10.1038/s41405-020-00050-5

31. Elchaghaby M A, Moheb D M, El Shahawy O I, Abd Alsamad A M, Rashed M A M. Clinical and Radiographic Evaluation of Indirect Pulp Treatment of Young Permanent Molars using Photo-Activated Oral Disinfection versus Calcium Hydroxide: A Randomized Clinical Trial. BDJ Open 2020; DOI: 10.1038/ s41405-020-0030-z.

32. Mummery T A, John M, Stokes S M. A quality improvement project to assess the use of preventative measures against acute alveolar osteitis. BDJ Open 2019; DOI: 10.1038/s41405-019-0019-7.

33. Kowash M, Al-Halabi M, Hussein I et al. A single-centre investigator-blinded randomised parallel-group study protocol to investigate the influence of an acclimatisation appointment on children's behaviour during N20/02 sedation as measured by psychological, behavioural and real-time physiological parameters. BDJ Open 2020; DOI: 10.1038/ s41405-020-0031-y.

34. Gandhi K K, Cappetta E G, Pavaskar R. Effectiveness of the adjunctive use of ozone and chlorhexidine in patients with chronic periodontitis. BDJ Open 2019; DOI: 10.1038/s41405-019-0025-9.

35. Habbab K M, D'Aiuto F, Habbab M A, Porter S R. Molecular Markers Relevant to Myocardial Injury Following Dental Extraction in Patients with and without Coronary Artery Disease. BDJ Open 2019; DOI: 10.1038/s41405-019-0018-8

36. Kroese J M, Volgenant C M C, van Schaardenburg D, Loos B G, Crielaard W, Lobbezoo F. Temporomandibular joint function, periodontal health, and oral microbiome in early rheumatoid arthritis and at-risk individuals: a prospective cohort study protocol. BDJ Open 2020; DOI: 10.1038/s41405-020-0034-8.

37. Iqbal Z, Kyzas P. Analysis of the critical dose of radiation therapy in the incidence of Osteoradionecrosis in head and neck cancer patients: A case series. BDJ Open 2020 DOI: 10.1038/s41405-020-00044-3.

38. Otero L, Lacunza E, Vasquez V, Arbelaez V, Cardier $\mathrm{F}$, González F. Variations in AXIN2 predict risk and prognosis of Colorectal Cancer. BDJ Open 2019; DOI: 10.1038/s41405-019-0022-z.

39. Thymi M, Visscher C M, Wismeijer D, Lobbezoo F. Associations between sleep bruxism and (peri-)implant complications: lessons learned from a clinical study. BDJ Open 2020; DOI: 10.1038/s41405-020-0028-6.

40. Ali A M M, Ahmed W H, Khattab N M. Applicability of Demirjian's Method for Dental Age Estimation in a Group of Egyptian Children. BDJ Open 2019; DOI: 10.1038/s41405-019-0015-y.

41. Chetty M, Roberts T, Shaik S, Beighton P. Dentinogenesis imperfecta in Osteogenesis Imperfecta type XI in South Africa: A Genotype-Phenotype Correlation. BDJ Open 2019; DOI: 10.1038/s41405-019-0014-z.

42. Vaahtoniemi L. The reciprocal jaw-muscle reflexes elicited by anterior- and back- tooth-contacts - a perspective to explain the control of the masticatory muscles. BDJ Open 2020; DOI: 10.1038/ s41405-020-00056-z.

43. Khan M, Kazmi S M R, Khan F R, Samejo I. Analysis of different characteristics of smile. BDJ Open 2020; DOI: 10.1038/s41405-020-0032-x.

44. Moosazadeh M, Gorji N E, Nasiri P, Shafaroudi A M. Comparison of Decayed, Missing, Filled Teeth index Between Thalassemia major Patients and Control Group: A Systematic review and Meta-analysis. BDJ Open 2020; DOI: 10.1038/s41405-020-00051-4.

45. Gallagher J E, KC S, Johnson I G et al. A Systematic Review of Contamination (Aerosol, Splatter and Droplet Generation) associated with Oral Surgery and its relevance to COVID-19. BDJ Open 2020; DOI: 10.1038/ s41405-020-00053-2. 